\title{
Effect of Hydrogen and Hydrogen Enriched Compressed Natural Gas Induction on the Performance of Rubber Seed Oil Methy Ester Fuelled Common Rail Direct Injection (CRDi) Dual Fuel Engines
}

\author{
Mallikarjun Bhovi1 ${ }^{1}$, N.R. Banapurmath²* S.V. Khandal ${ }^{2}$, V.S. Yaliwal ${ }^{3}$ \\ ${ }^{1}$ Department of Mechanical Engineering, P.D.A. College of Engineering, Gulburga, Karnataka, India \\ ${ }^{2}$ Department of Mechanical Engineering, B.V.B College of Engineering and Technology, Hubli, Karnataka, India \\ ${ }^{3}$ Department of Mechanical Engineering, S.D.M. College of Engineering and Technology, Hubli, Karnataka, India
}

*Corresponding Author: nr_banapurmath@rediffmail.com

Citation: Bhovi, M., Banapurmath, N.R., Khandal, S.V. and Yaliwal, V.S. (2017). Effect of Hydrogen and Hydrogen Enriched Compressed Natural Gas Induction on the Performance of Rubber Seed Oil Methy Ester Fuelled Common Rail Direct Injection (CRDi) Dual Fuel Engines. European Journal of Sustainable Research, 1(2), 07.

doi: $10.20897 /$ ejosdr.201707

Published: June 15, 2017

\begin{abstract}
Renewable fuels are in biodegradable nature and they tender good energy security and foreign exchange savings. In addition they address environmental concerns and socio-economic issues. The present work presents the experimental investigations carried out on the utilization of such renewable fuel combinations for diesel engine applications. For this a single-cylinder four-stroke water cooled direct injection (DI) compression ignition (CI) engine provided with CMFIS (Conventional Mechanical Fuel Injection System) was rightfully converted to operate with CRDi injection systems enabling high pressure injection of Rubber seed oil methyl ester (RuOME) in the dual fuel mode with induction of varied gas flow rates of hydrogen and hydrogen enriched CNG (HCNG) gas combinations. Experimental investigations showed a considerable improvement in dual fuel engine performance with acceptable brake thermal efficiency and reduced emissions of smoke, hydrocarbon (HC), carbon monoxide (CO) and slightly increased nitric oxide (NOx) emission levels for increased hydrogen and HCNG flow rates. Further CRDi facilitated dual fuel engine showed improved engine performance compared to CMFIS as the former enabled high pressure (900 bar) injection of the RuOME and closer to TDC (Top Dead Centre) as well. Combustion parameters such as ignition delay, combustion duration, pressure-crank angle and heat release rates were analyzed and compared with baseline data generated. Combustion analysis showed that the rapid rate of burning of hydrogen and HCNG along with air mixtures increased due to presence of hydrogen in total and in partial combination with $\mathrm{CNG}$ which further resulted into higher cylinder pressures and energy release rates. However, sustained research that can provide feasible engine technology operating on such fuels in dual fuel operation can pave the way for continued fossil fuel usage.
\end{abstract}

Keywords: rubber oil methyl ester (RuOME), dual-fuel engine, flow rate, emissions, carburetor

\section{INTRODUCTION}

Compression ignition (CI) engines are used mainly for power generation applications due to higher performance, reliability, and durability. In the present energy scenario, conventional fuel are depleting while the energy demand is rising at a quicker rate. In addition, stringent environmental legislations put by the government is also one of the reason to use of environment friendly fuels (biofuels) in partial or in complete substitute for 
diesel engine applications. This is the need of the hour for India and rest of the world. However, major disadvantage of diesel engine is that, it emits higher smoke and nitric oxide emissions [1,2]. These pollutants can be suitably reduced to acceptable norms by replacing fossil fuels with Biofuels in a phased manner. In this context, investigators conducted experiments on diesel engine using various fuel additives and strategies (water-diesel emulsion, and direct water injection, and mixing of known quantity of water into the inlet manifold etc) to enhance the performance and reduce emission levels (Khalife et al 2017). Problems involved in using fuel additive, their respective advantages and problems have been reported. However, use of fuel additive play a very significant role during combustion and enhanced performance with reduced emission levels has been reported (Imdadul et al 2016). However, diesel engine fueled with biodiesel alone can result into reduced smoke and nitric oxide emissions [3]. Several researchers have investigated the use of alternative fuels in diesel engines to achieve specific goals. Several investigators reported that performance of diesel engine is significantly affected by type of injector used and air-fuel ratio [Thangaraja J et.al, 2015, Yaliwal VS. et.al, 2016, Bhuiya MMK, et.al, 2016, Ying Wang, et.al, 2016, RS Hosmath et.al, 2016]. Air and fuel mixing is noticeably affected by the nozzle spray characteristics and air flow produced within the engine cylinder. Altering the fuel properties and engine design modifications has an effect on the different phases of heat release shape and magnitude. To prevent knocking and have highest performance, control of heat release rate is significant to limit cylinder pressure [Yaliwal VS. et.al, 2016, Hosmath RS. et.al, 2016].

Use of gaseous fuels in compression ignition (CI) engine operated in dual fuel mode leads to combustion with complexity due to combustion of more than one fuel with dissimilar properties and is burnt simultaneously inside the engine cylinder. Dual fuel engine technology lowers the consumption of liquid fuel usage and reduces the smoke and nitric oxide levels in the exhaust. Employing renewable liquid and gaseous fuels of biodiesel, HCNG and hydrogen in dual fuel engine is an attractive option for sustained energy security to India and for rest of the world. Therefore, utilization of Biofuels for engine applications can improve the economy by limiting the crude petroleum imports. Utilization of CNG in diesel engines in dual fuel mode results in higher HC/CO emissions with lower power output compared to diesel alone operation. Therefore, addition of hydrogen in $\mathrm{CNG}$ can improve the engine performance with lower emission levels. This is because the hydrogen in CNG burns cooler than CNG resulting in higher power and lower exhaust gas temperatures (EGT).Published literatures propose that non-premixed flame steadiness gets improved by mixing CNG with hydrogen addition [RS Hosmath et.al, 2016].

Compressed natural gas (CNG) has lower flame speed, and it can be improved by enriching CNG with hydrogen. $\mathrm{CNG}$ and $\mathrm{H}_{2}$ cannot be directly used as lone fuels in diesel engines because of their lower cetane number and higher self-ignition temperature $(858 \mathrm{~K})$, but can be used in dual fuel mode with appropriate pilot fuel injection [Akhilendra PS, 2016, Paul A 2013]. Hydrogen has higher burning velocity and is six times higher than gasoline and hence it favors combustion. Wider hydrogen flammability range $(0.1<\varnothing<7.1)$, allows engines to run stably under highly unfavorable conditions, with enhanced performance and reduced emission levels. Studies on dual fuel engines with HCNG induction showed better performance and can eventually provide partial replacement for petroleum based fuels. The liquid fuels injected into dual-fuel engine with hydrogen enriched CNG, hydrogen enriched producer gas and their associated combustion process in a diesel engine was investigated by several investigators [Saravanan N, et.al. 2008, 2010, Yaliwal VS, et.al, 2016, Qian YJ, et. al. 2011, Lee JT, et. al. 2002]. Performance of engines with intake port injection was reported to be superior to in-cylinder injection at all equivalence ratios studied. At a compression ratio of 24.5, 30\% efficiency of has been reported [Masood M et.al. 2007]. Engine load and amount of hydrogen addition to CNG significantly affect the engine power output and emission levels. Cylinder pressure was comparatively higher when the engine load was higher and safety aspects are necessary to be adopted due to knocking tendency of engine. Performance and emissions and cyclic variations of in-cylinder pressure with the use of hydrogen in dual fuel engine have been reported [Apostolescu N, et. al, 1996]. Study on hydrogen fueled engines has been reported in the literature [M Senthil Kumar, et. al, 2014].

In view of this, trial engine tests were carried out on a single-cylinder four-stroke water-cooled DI diesel engine operated in dual-fuel mode with both versions of CMFIS and CRDi injection systems using RuOME and gaseous fuels of HCNG (20\% Hydrogen enriched CNG) and hydrogen induction at optimized engine parameters, and the results were analyzed and compared with base line data. For CMFIS dual fuel engine the optimized engine parameters of $27^{\circ} \mathrm{BTDC}, 240 \mathrm{bar}, 4$ hole injector with $0.2 \mathrm{~mm}$ orifice and reentrant combustion chamber were used. While in CRDi assisted dual fuel engine optimized parameters of 10 BTDC injection timing, 900 bar injection opening pressure, 6-hole injector with $0.1 \mathrm{~mm}$ orifice and reentrant combustion chamber were used respectively.

\section{FUEL PROPERTIES}

Rubber seed oil was used as the secondary injected fuel while the gaseous fuels of HCNG and hydrogen were used as the primary inducted fuels in the converted diesel engine to operate in dual fuel mode. Rubber seed oil was subsequently converted into its respective biodiesel called Rubber Seed Oil Methyl Ester (RuOME) using well established transesterification process and was used as the pilot injected fuel. The properties of Rubber Seed oil 
and RuOME were obtained and are recapitulated in Table 1. Gaseous fuels, viz, CNG, HCNG and Hydrogen are shown in Table 2.

Table 1. Properties of Fuels Used.

\begin{tabular}{|l|l|l|l|l|l|}
\hline S1. No. & Properties & Diesel & Rubber Seed oil & RuOME & ASTM standard \\
\hline 1 & Chemical Formula & C13H24 & --- & --- & \\
\hline 2 & Density $(\mathrm{kg} / \mathrm{m} 3)$ & 840 & 915 & 880 & D1298 \\
\hline 3 & Calorific value $(\mathrm{kJ} / \mathrm{kg})$ & 43,000 & 35600 & 36,010 & $\mathrm{D} 2382$ \\
\hline 4 & Viscosity at 40oC $(\mathrm{cSt} *)$ & $2-5$ & 45.65 & 5.5 & $\mathrm{D} 445$ \\
\hline 5 & Flashpoint $(\mathrm{oC})$ & 75 & 215 & 167 & $\mathrm{D} 93$ \\
\hline 6 & Cetane Number & $45-55$ & 42 & 45 & --- \\
\hline 7 & Carbon Residue $(\%)$ & 0.1 & 0.66 & ---- & D4530 \\
\hline 8 & Cloud point & -2 & --- & 7 & D2500 \\
\hline 9 & Pour point & -5 & --- & 4 & D97 \\
\hline 10 & Molecular weight & 181 & --- & 227 & --- \\
\hline 11 & Auto ignition temperature $(\mathrm{oC})$ & 260 & & 470 & --- \\
\hline 12 & Ash content $\%$ by mass & 0.57 & & 0.01 & D482 \\
\hline 13 & Oxidation stability & High & Low & Low & --- \\
\hline 14 & Sulphur Content & High & No & No & --- \\
\hline
\end{tabular}

Table 2. Properties of CNG, and HCNG.

\begin{tabular}{|c|c|c|c|c|}
\hline S1. No & Properties & CNG & HCNG & Hydrogen \\
\hline 1 & $\begin{array}{l}\text { Density of Liquid at } \\
15 \mathrm{o}, \mathrm{kg} / \mathrm{m} 3\end{array}$ & 0.77 & $\mid--$ & 0.0838 \\
\hline 3 & Boiling Point, K & $147 \mathrm{~K}$ & -- & \\
\hline 4 & $\begin{array}{l}\text { Lower calorific } \\
\text { value, } \mathrm{kJ} / \mathrm{kg}\end{array}$ & 48000 & 47170 & 119930 \\
\hline 5 & \begin{tabular}{|l|} 
Limits of \\
Flammability in air, \\
vol. $\%$
\end{tabular} & $5-15$ & $5-35$ & $4-75$ \\
\hline 6 & $\begin{array}{|ll|}\text { Auto } & \text { Ignition } \\
\text { Temp, K } & \\
\end{array}$ & 813 & 825 & 858 \\
\hline 7 & $\begin{array}{l}\text { Theoretical Max } \\
\text { flame Temp, K }\end{array}$ & 2148 & 2210 & \\
\hline 8 & Flash point $0 \mathrm{C}$ & 124 & - & \\
\hline 9 & Octane number & 120 & -- & 130 \\
\hline 10 & $\begin{array}{|ll|}\begin{array}{l}\text { Burning } \\
\mathrm{cm} / \mathrm{sec}\end{array} & \text { velocity, } \\
\end{array}$ & 45 & 110 & \\
\hline 11 & $\begin{array}{l}\text { Stoichiometric } \\
\mathrm{A} / \mathrm{F}, \mathrm{kg} \text { of air } / \mathrm{kg} \\
\text { of fuel }\end{array}$ & $17: 1$ & -- & 34.3 \\
\hline 12 & $\begin{array}{l}\text { Flame temperature, } \\
\text { OC }\end{array}$ & -- & 1927 & \\
\hline 13 & Equivalence ratio & $0.7-40$ & $0.5-5.4$ & \\
\hline
\end{tabular}

\section{EXPERIMENTAL SET-UP}

The experimental set-up of modified diesel dual-fuel engine with CMFIS and CRDi arrangements fueled on RuOME and hydrogen and HCNG induction is shown in Figure 1. Trial tests were carried out on a four-stroke single cylinder water-cooled DI compression ignition engine with a displacement volume of $662 \mathrm{cc}$, compression 


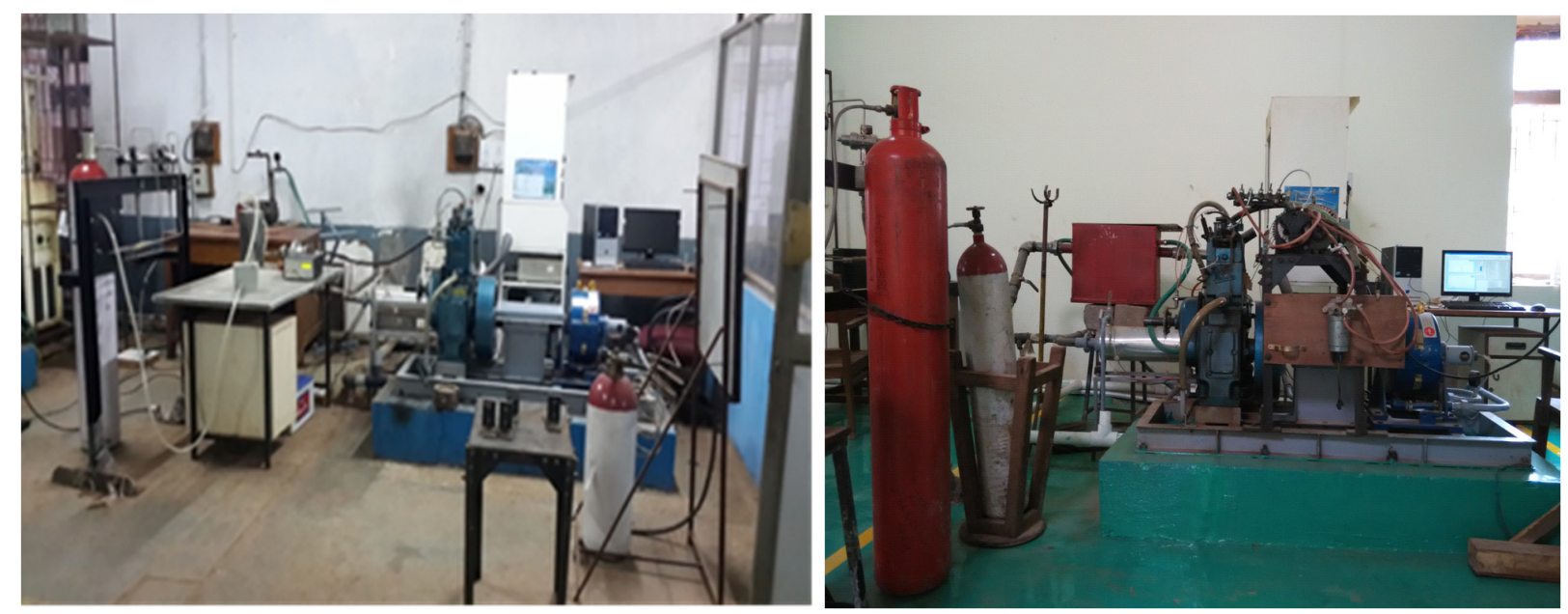

Figure 1. Hybrid model of continuity and availability management
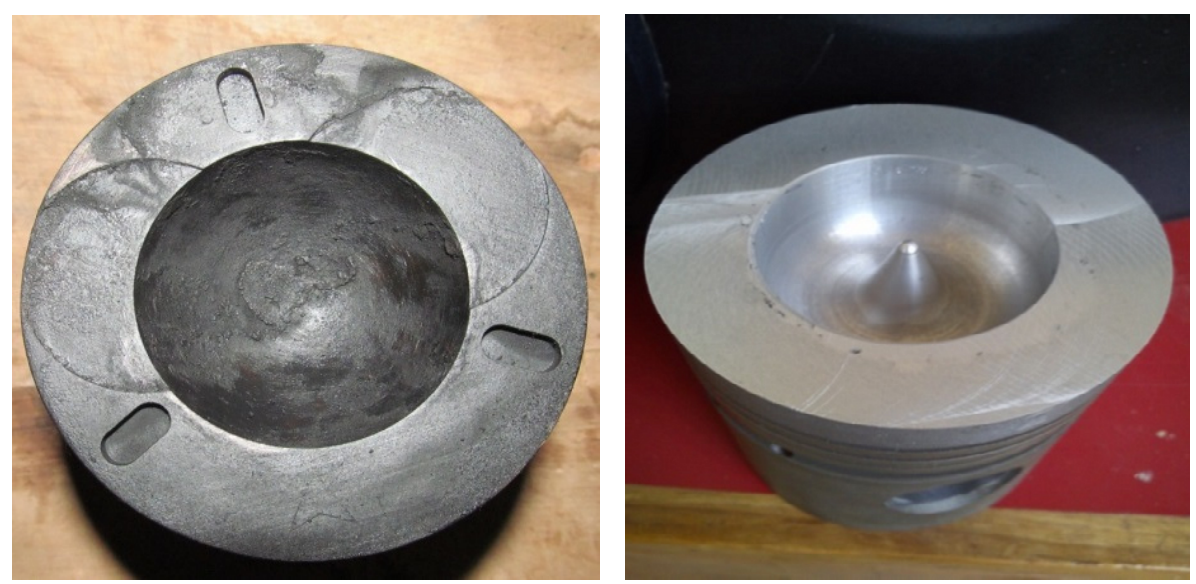

Figure 2. Combustion chamber shapes adopted in the study

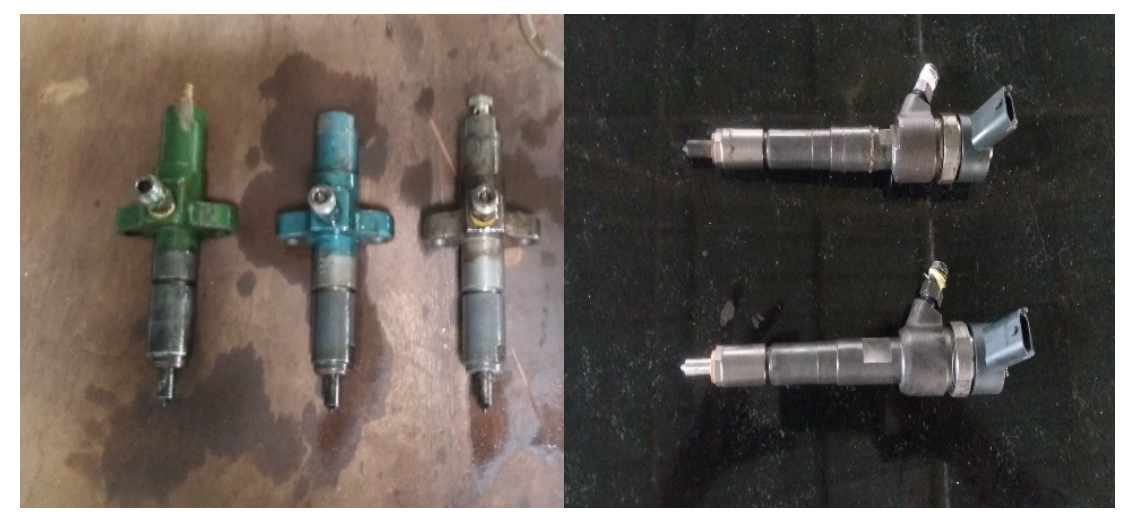

Figure 3. CMFIS and CRDi injectors

ratio of $17.5: 1$ and developing power of $5.2 \mathrm{~kW}$ at $1500 \mathrm{rev} / \mathrm{min}$. The engine is consisting of conventional fuel injection system, hemispherical combustion chamber with overhead valves and governor to control engine speed. The injector opening pressure and the static injection timing as specified by the manufacturer were 205 bar and 23 Before Top Dead Centre (BTDC), respectively. However, for the study reentrant combustion chamber shape was optimized. Figure 2 shows combustion chamber shapes adopted in the study. Figure 3 shows the injectors used in the study. Engine is cooled continuously by accomplishing circulating water through the water jackets present in the engine block and cylinder head. To measure cylinder pressure a piezoelectric pressure transducer was located on the cylinder head. Hartridge smoke meter and exhaust gas analyzer and were used to measure smoke, $\mathrm{HC}, \mathrm{CO}$, and $\mathrm{NO}_{\mathrm{x}}$ emissions respectively. Table 3,4 and 5 shows the specification of the engine, Hartridge smoke meter and exhaust gas analyzer used in the study. 
European Journal of Sustainable Development Research, 1:2 (2017), 07

Table 3. Specifications of the CI engine.

\begin{tabular}{|l|l|l|}
\hline S1 No & Parameters & Specification \\
\hline 2 & Type & TV1 ( Kirloskar make) \\
\hline 3 & Software used & Engine soft \\
\hline 4 & Nozzle opening pressure & 200 to 225 bar \\
\hline 5 & Governor type & Mechanical centrifugal type \\
\hline 6 & No of cylinders & Single cylinder \\
\hline 7 & No of strokes & Four stroke \\
\hline 8 & Fuel & H. S. Diesel \\
\hline 9 & Rated power & $5.2 \mathrm{~kW}$ ( $\mathrm{HP}$ at $1500 \mathrm{RPM})$ \\
\hline 10 & Cylinder diameter (Bore) & $0.0875 \mathrm{~m}$ \\
\hline 11 & Stroke length & $0.11 \mathrm{~m}$ \\
\hline 12 & Compression ratio & $17.5: 1$ \\
\hline Air Measurement Manometer: & \\
\hline 13 & Made & MX 201 \\
\hline 14 & Type & U- Type \\
\hline 15 & Range & $100-0-100 \mathrm{~mm}$ \\
\hline Eddy current dynamometer: & \multicolumn{2}{|l|}{} \\
\hline 16 & Model & AG -10 \\
\hline 17 & Type & Eddy current \\
\hline 18 & Maximum & 7.5 (kW at 1500 to 3000 RPM) \\
\hline 19 & Flow & Water must flow through Dynamometer during the use \\
\hline 20 & Dynamometer arm length & $0.180 \mathrm{~m}$ \\
\hline 21 & Fuel measuring unit - Range & 0 to 50 ml \\
\hline
\end{tabular}

Table 4. Specifications of exhaust gas analyzer.

\begin{tabular}{|c|c|c|c|}
\hline Type & DELTA $1600 \mathrm{~S}$ & & \\
\hline Object of Measurement & $\begin{array}{lll}\text { Carbon monoxide } & (\mathrm{CO}), & \text { Carbon } \\
\text { and Hydrocarbons }(\mathrm{HC}) & \end{array}$ & Dioxide & $(\mathrm{CO} 2)$ \\
\hline Range of Measurement & $\begin{array}{l}\mathrm{HC}=0 \text { to } 20,000 \mathrm{ppm} \text { as } \mathrm{C} 3 \mathrm{H} 8 \text { (Propane) } \\
\mathrm{CO}=0 \text { to } 10 \% \\
\mathrm{CO} 2=0 \text { to } 16 \% \\
\mathrm{O} 2=0 \text { to } 21 \% \\
=0 \text { to } 5000 \mathrm{ppm} \text { (as Nitric Oxide) }\end{array}$ & & NOX \\
\hline Accuracy & $\begin{array}{l}\mathrm{HC}=+/-30 \mathrm{ppm} \mathrm{HC} \\
\mathrm{CO}=+/-0.2 \% \mathrm{CO} \\
\mathrm{CO} 2=+/-1 \% \mathrm{CO} 2 \\
\mathrm{O} 2=+/-0.2 \% \mathrm{O} 2 \\
\mathrm{NOX}=+/-10 \mathrm{ppm} \mathrm{NO}\end{array}$ & & \\
\hline Resolution & $\begin{array}{l}\mathrm{HC}=1 \mathrm{ppm} \\
\mathrm{CO}=0.01 \% \text { Vol} \\
\mathrm{CO} 2=0.1 \% \text { Vol. } \\
\mathrm{O} 2=0.01 \% \text { Vol. } \\
\mathrm{NOX}=1 \mathrm{ppm}\end{array}$ & & \\
\hline Warm up time & $10 \mathrm{~min}$. (self controlled) at $200 \mathrm{C}$ & & \\
\hline Speed of Response Time & Within $15 \mathrm{sec}$. for $90 \%$ response & & \\
\hline Sampling & Directly sampled from tail pipe & & \\
\hline Power Source & 100 to $240 \mathrm{~V} \mathrm{AC} / 50 \mathrm{~Hz}$ & & \\
\hline Weight & $800 \mathrm{~g}$ & & \\
\hline Size & $100 \mathrm{~mm} \times 210 \mathrm{~mm} \times 50 \mathrm{~mm}$ & & \\
\hline
\end{tabular}


Table 5. Specifications of smoke meter.

\begin{tabular}{|l|l|}
\hline Type & HARTRIDGE SMOKEMETER-4 \\
\hline Object of Measurement & Smoke \\
\hline Measuring range opacity & $0-100 \%$ \\
\hline Accuracy & $+/-2 \%$ relative \\
\hline Resolution & $0.1 \%$ \\
\hline Smoke length & $0.43 \mathrm{~m}$ \\
\hline Ambient Temperature Range & $-50 \mathrm{C}$ to $+450 \mathrm{C}$ \\
\hline Warm up time & $10 \mathrm{~min}$. (self controlled) at 200C \\
\hline Speed of Response Time & Within 15 sec. for $90 \%$ response \\
\hline Sampling & Directly sampled from tail pipe \\
\hline Power Supply & $\begin{array}{l}100 \text { to } 240 \mathrm{~V} \text { AC / } 50 \mathrm{HZ} \\
10-16 \mathrm{~V} \text { DC } @ 15 \text { amps }\end{array}$ \\
\hline Size & $100 \mathrm{~mm}$ x $210 \mathrm{~mm} \times 50 \mathrm{~mm}$. \\
\hline
\end{tabular}

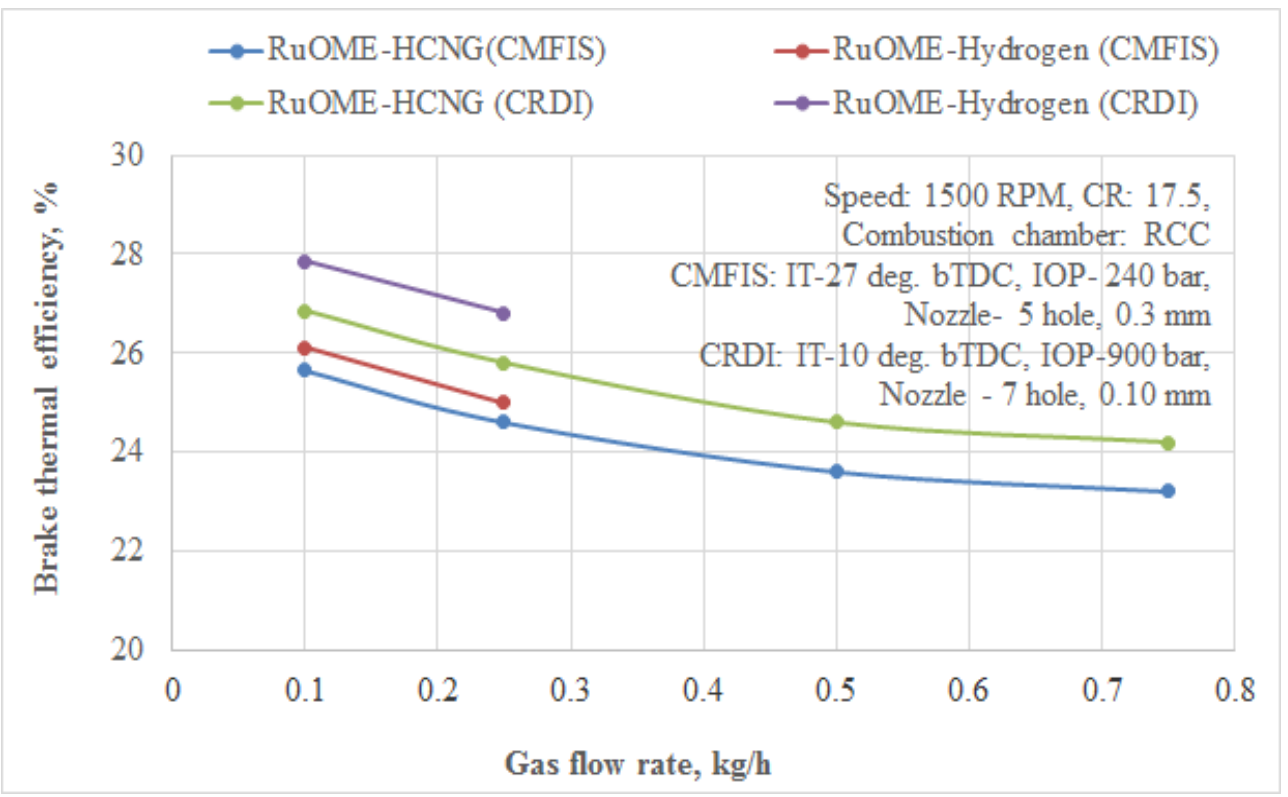

Figure 4. Effect of gaseous fuel flow rate $(\mathrm{kg} / \mathrm{h})$ on the BTE

\section{RESULTS AND DISCUSSIONS}

This section discusses the effect of hydrogen and HCNG gas flow rates on the performance of biodiesel injected dual fuel engine. HCNG flow rates were varied from 0.10 to $0.75 \mathrm{~kg} / \mathrm{h}$, while hydrogen flow rates was varied from 0.1 to $0.25 \mathrm{~kg} / \mathrm{h}$ due to engine limited operating conditions. The increased gas flow rates of HCNG beyond $0.75 \mathrm{~kg} / \mathrm{h}$ and that of Hydrogen beyond $0.25 \mathrm{~kg} / \mathrm{h}$ tends to cause engine knock leading to poor performance of the engine and hence the results of the same are not reported.

\section{Performance characteristics:}

The effect of gaseous fuel flow rate on brake thermal efficiency (BTE) of dual fuel engine with selected fuels combinations at 80\% load is shown in Figure 4. BTE decreased with increased gaseous flow rates of HCNG and hydrogen respectively. Incomplete burning of pilot ROME fuel injected associated with reduction in air entrapment due to gases inducted and decreased ignition sources could be responsible for the trends obtained.BTE further decreased with increase inthe gaseous fuel escaping from the combustion. As the gas flow rates were increased from 0.25 to $0.75 \mathrm{~kg} / \mathrm{h}$, the BTE was decreased due to addition of both HCNG and hydrogen to the intake air as it lowered the volumetric efficiency. At lower gas flow rates, the higher liquid fuel pilot quantities improve gaseous fuel utilization. Increased BTE were found for CRDI operation due to higher injection pressures as compared to both CMFIS operation and such high pressure injection are more suitable for heavier biodiesel operation. Higher calorific value of HCNG and higher flame velocity of hydrogen in CNG improves the 


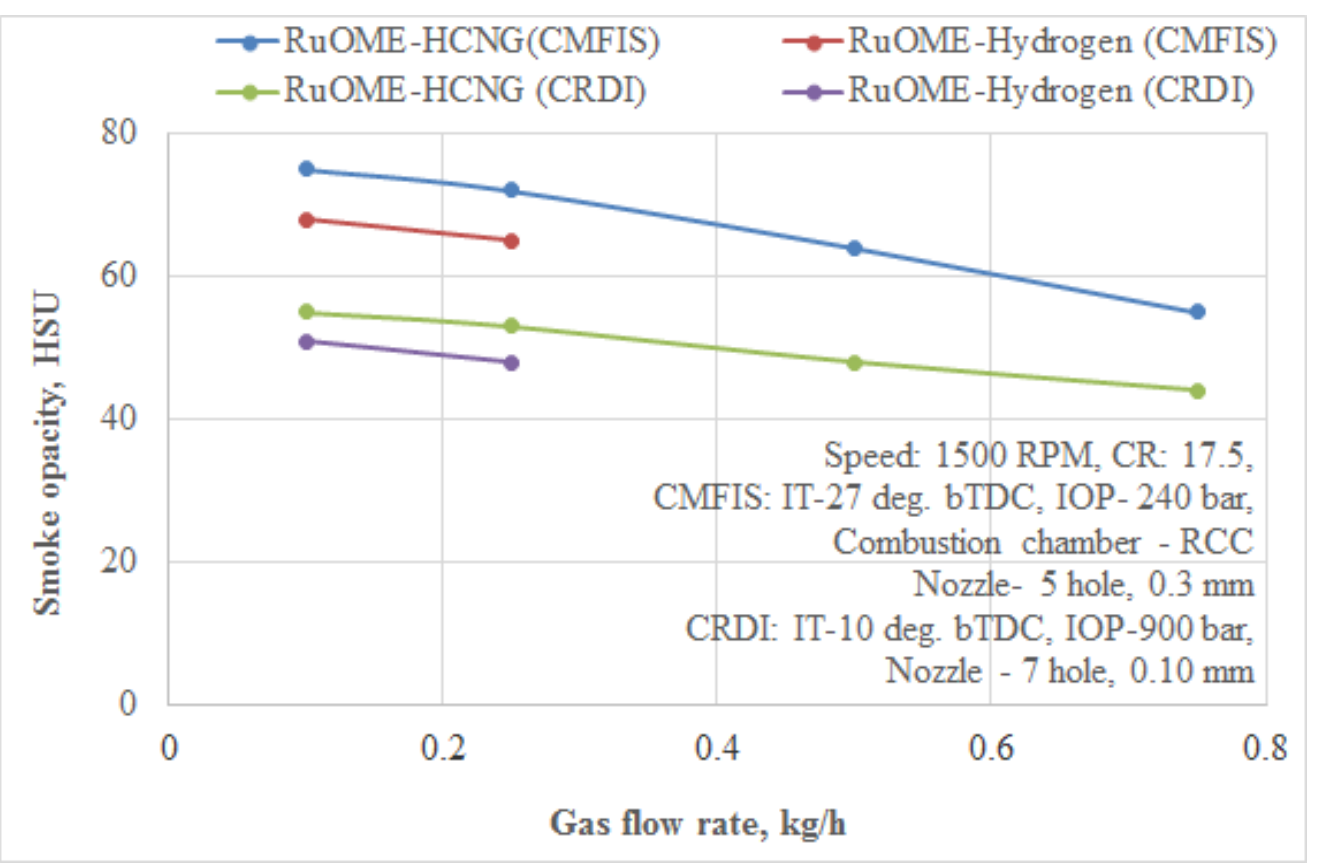

Figure 5. Effect of gaseous fuel flow rate $(\mathrm{kg} / \mathrm{h})$ on the smoke emission

performance in CRDi versions of injection systems. In addition, hydrogen presence in CNG allows the lean burn limit to be extended due to fast burn rate of hydrogen. BTE was further improved with hydrogen induction compared to the HCNG operation. The expansion of the flammability limit in-turn significantly lowers heat loss by increased combustion temperature and heat transfer. Hydrogen fast burn rate sources the combustion duration to lower. This leads to increased heat release rate and exhaust NOx with an increased hydrogen percentage. It is thus observed that with increased flow rate of hydrogen the BTE was decreased. This could be due to improper utilization of Hydrogen during combustion. For the gaseous fuel operation with CRDI system, HCNG with ROME fuel combination resulted in slightly higher BTE compared to CMFIS operation. Results showed that ROME-HCNG (CRDI) dual fuel engines resulted in improved performance, but at higher flow rates of HCNG engine tend to suffer from premature ignition or sever knocking. For the same flow rate of HCNG and hydrogen with $0.1 \mathrm{~kg} / \mathrm{h}$, RuOME-Hydrogen with CRDI resulted in $3.8 \%$ increased brake thermal efficiency compared to RuOME-HCNG with CMFIS, respectively.

\section{Emission Characteristics}

The effect of gaseous flow rates on the smoke opacity for both CMFIS and CRDI dual fuel engine operation is shown in Figure 5. Lower smoke levels have been observed with increased gaseous flow rates and this could be due to lower $\mathrm{C} / \mathrm{H}$ ratio in the fuel combinations used. At higher flow rates of gaseous fuel induction, drastic reduction in smoke levels has been observed. This could be due to use of low carbon fuel and enhanced temperature of the gases inside the cylinder which favors the better oxidation with a fuel. However, at lower flow rate of gaseous fuel induction, smoke density marginally increased due to partial burning of the injected liquid fuel. Injected fuel being same, type of injection system (CMFIS or CRDi) and properties of inducted gaseous fuel used plays major role during engine combustion. Major advantage of dual fuel engine with HCNG induction is that the smoke emissions were lowered with CRDi operation compared to CMFIS operation for the same injected liquid fuel. This may be due to lowered carbon content and faster burning rates associated with clean burning nature of hydrogen followed by HCNG with CRDi system when compared to CMFIS. The increased burning velocity and hydrogen flame temperature followed by HCNG leads to comparatively better burning in CRDi dual fuel engine operation. For the same flow rate of HCNG and hydrogen $(0.1 \mathrm{~kg} / \mathrm{h})$, RuOME injected with CRDi facility resulted into $14.2 \%$ decreased smoke opacity when compared to RuOME-HCNG with CMFIS, respectively.

HC emission level variations for both CMFIS and CRDi dual fuel engine operation for different gas flow rates are presented in Figure 6. Hydrocarbon emission levels were found to be higher for increased gas flow rates. Relatively poor mixing rate and insufficient air supply may be responsible for these trends. The lower BTE associated with higher gas flow rate could also be responsible for this behavior. Increased HCNG and hydrogen flow rates resulted into higher HC emissions, but with RuOME injection in CRDi showed decreased HC emissions. The hydrocarbon emission levels in the engine exhaust with dual fuel operation is higher due to the fact that the gaseous fuel which causes combustion at a low-temperature, leading to poor combustion caused by the small quantity of pilot fuel cannot propagate longer distance to burn the complete premixed mixture. Further, collection 


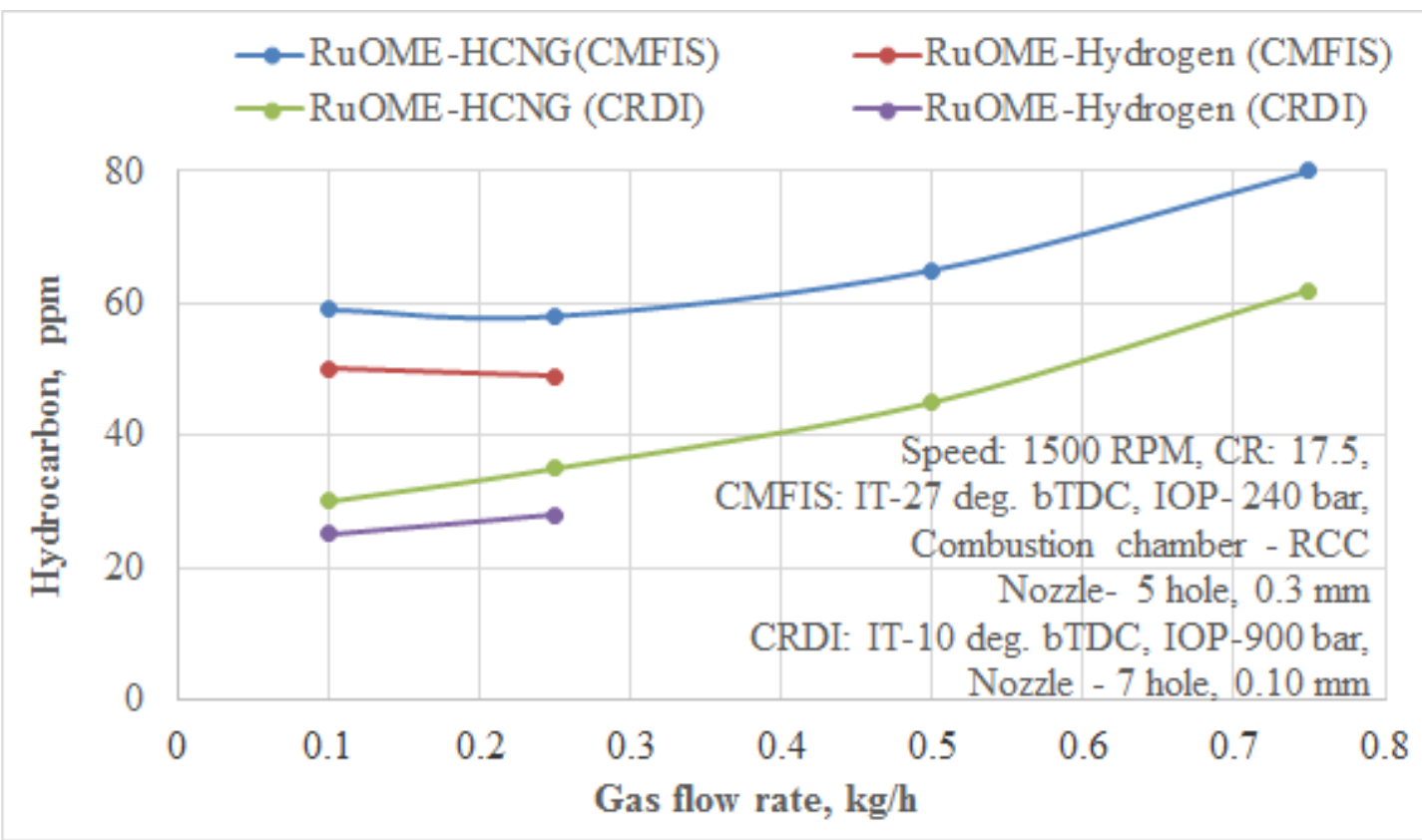

Figure 6. Effect of gaseous fuel flow rate $(\mathrm{kg} / \mathrm{h})$ on the $\mathrm{HC}$ emission

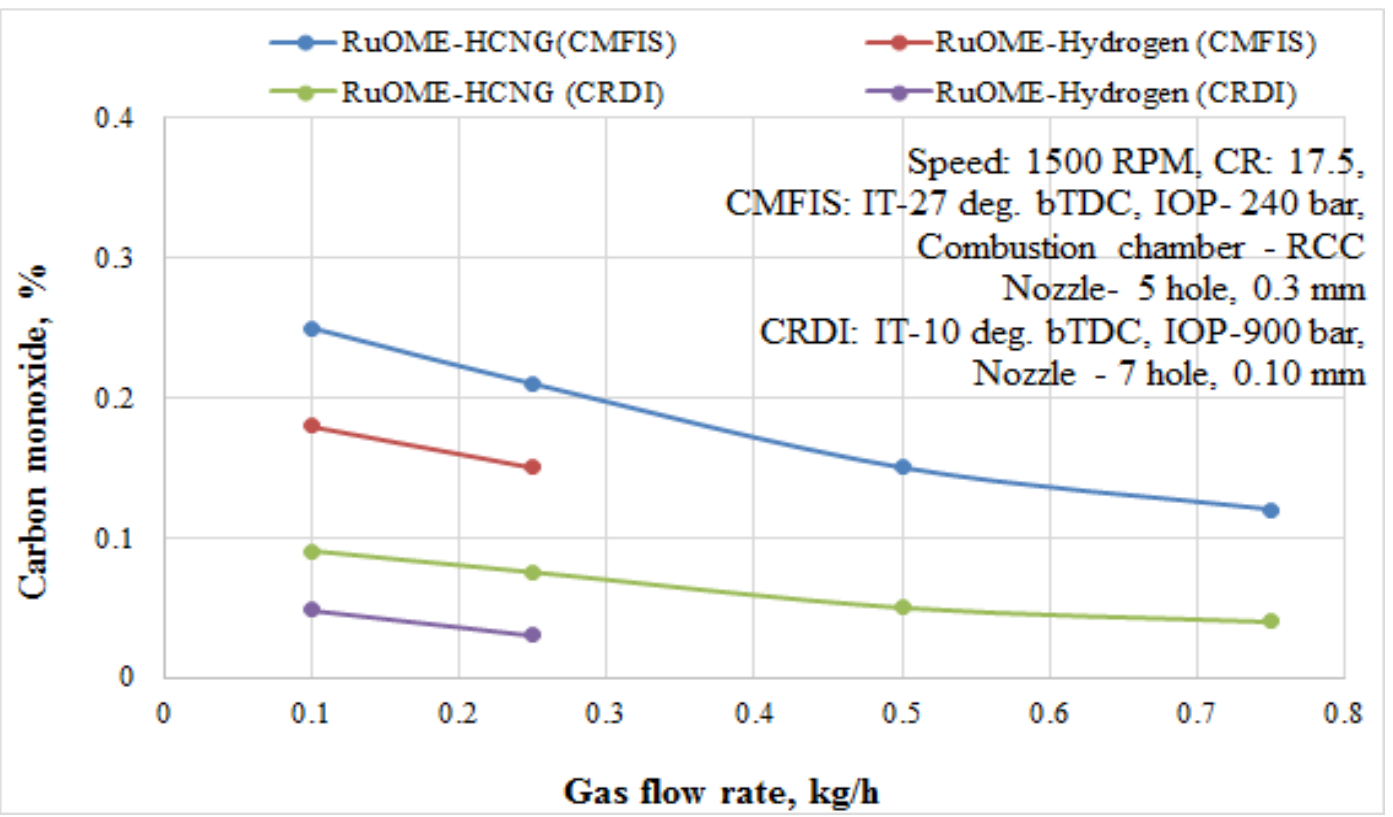

Figure 7. Effect of gaseous fuel flow rate $(\mathrm{kg} / \mathrm{h})$ on the $\mathrm{CO}$ emission

unburnt fuel in the crevice region during the event of compression and ignition may become as main source of $\mathrm{HC}$ emissions. For selected injected liquid fuel of RuOME, the properties of the gases inducted resulted in varied HC emission behavior and accordingly RuOME-Hydrogen operation resulted in decreased HC emissions compared to RuOME-HCNG operation. The dual fuel operation with Hydrogen gives a strong reduction of unburned hydrocarbon emission which results in more complete combustion. In addition Hydrogen has lower $\mathrm{H} / \mathrm{C}$ ratio, which drastically lowers the carbon based emissions. Hydrogen presence during dual fuel operation has higher flame velocity and flame temperature leading to better combustion. For $0.1 \mathrm{~kg} / \mathrm{h}$ flow rate of HCNG and hydrogen with high pressure injection of RuOME in CRDI resulted in $11.5 \%$ decreased HC when compared to CMFIS, respectively.

The variations of CO emission levels for both CMFIS and CRDidual fuel engine operation are presented in Figure 7. The premixed combustion of RuOME - HCNG (CRDi) results in more heat release rate leading to lower CO emissions compared to RuOME - HCNG (CMFIS) operation. Moreover CO emissions mainly depend on stoichiometric air-fuel ratio and combustion with rich mixture leading to higher $\mathrm{CO}$ emissions. Hence enhanced HCNG flow rate tends to decrease combustion rate due to poor utilization of gaseous fuel resulting into higher $\mathrm{CO}$ formations. However, it is observed that the $\mathrm{CO}$ emissions were further decreased with hydrogen flow rate during dual fuel operation. Some researchers reported lowered CO emission levels in the exhaust with reduced 


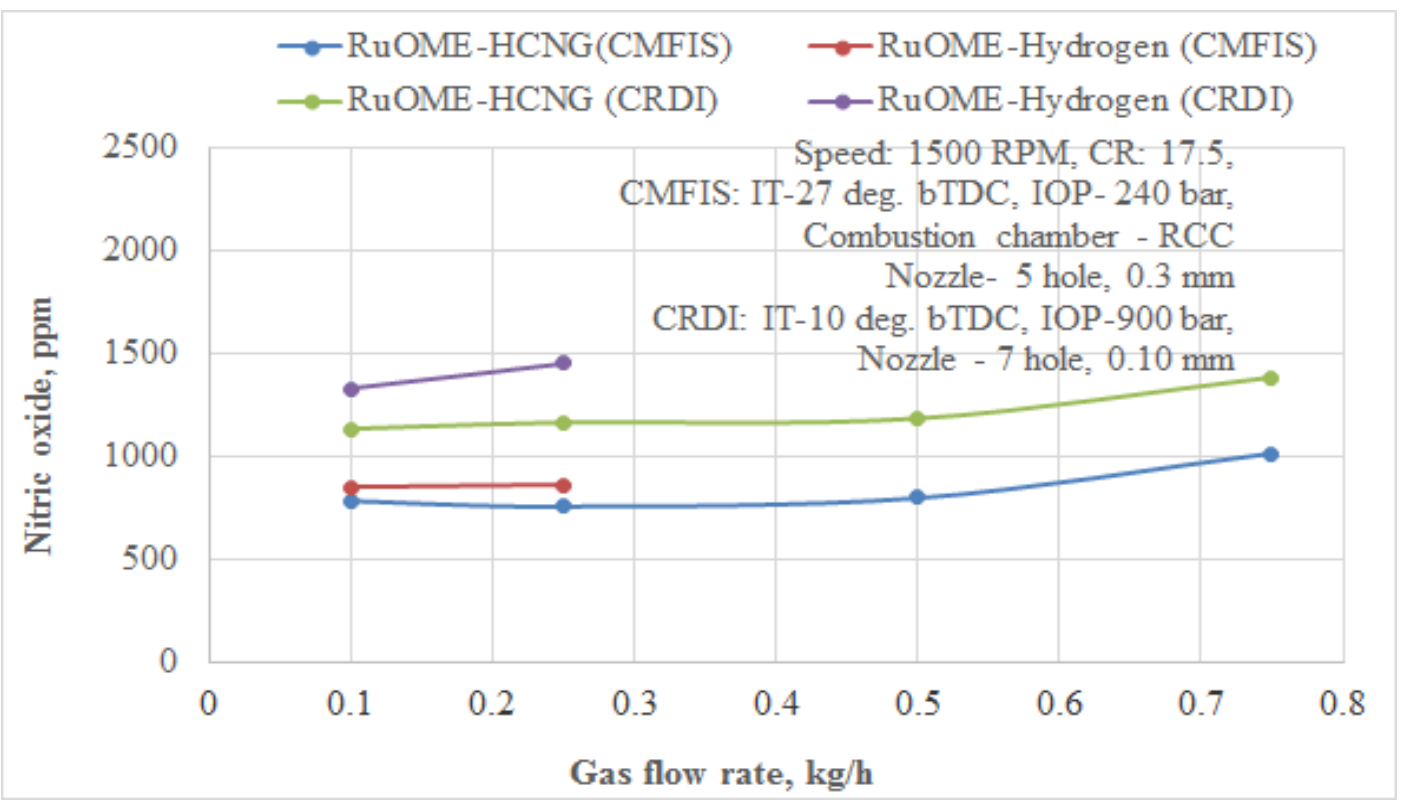

Figure 8. Effect of gaseous fuel flow rate $(\mathrm{kg} / \mathrm{h})$ on the NOx emission

flow rates and amplified CO levels with increased gaseous fuel supply for certain extent and later on begin to decrease (Hosmath et al., 2016). The increased gas flow rates of HCNG beyond $0.75 \mathrm{~kg} / \mathrm{h}$ and HCNG at 0.25 $\mathrm{kg} / \mathrm{h}$ inclines to knocking. Further it can lead to poor performance of the engine. Higher CO emission levels were observed for RuOME - HCNG (CMFIS) combination compared to RuOME-HCNG (CRDi) operation. This could be due to better combustion of HCNG with high pressure injected RuOME ensuring proper mixing of fuel combinations. However, CO emissions levels were further lowered with Hydrogen CRDi dual fuel operation compared to CMFIS operation. The burning temperatures were larger with Hydrogen and hence engine operates with hotter which in turn help better combustion. For $0.1 \mathrm{~kg} / \mathrm{h}$ flow rate of HCNG and hydrogen with high pressure pilot fuel injection of RuOME in CRDi engine resulted in $32.2 \%$ decreased CO compared to RuOMEHCNG with CMFIS, respectively.

Effect of low and high pressure injection of biodiesel with CMFIS and CRDi facilities and varied gas flow rates on dual fuel engine NOx emission levels is presented in Figure 8. The generation of nitrogen oxide is favored by increased oxygen concentration and combustion temperatures prevailing inside the engine cylinder. Higher NOx levels were observed for (CRDi) dual fuel operation fuelled on RuOME-HCNG when compared to CMFIS operation and it could be due to higher premixed combustion phase observed during the former high pressure injection system. This could be due to improper utilization of fuel combination in CMFIS version compared to CRDi operation. Higher biodiesel utilization to produce same power output leads to delayed injection which resulted into lowered NOx emissions. Increased gas flow rates further results in to higher NOx in general and hydrogen induction in particular showed higher magnitudes of NOx for the selected fuel combinations. Compared to RuOME-hydrogen (CMFIS) operation, it is observed that the CRDi operation resulted in higher NOx emissions. It could be due to increased pre-mixed combustion phase obtained with hydrogen induction associated with increased flame temperature which increased the $\mathrm{NO}_{\mathrm{x}}$ emissions. For the same flow rate of HCNG and hydrogen $(0.1 \mathrm{~kg} / \mathrm{h})$, RuOME-Hydrogen with CRDi resulted into $12.6 \%$ increased nitric oxide when compared to CMFIS, respectively.

\section{Combustion Characteristics}

Variation of ignition delay and combustion duration for CMFIS and CRDi facilitated dual fuel engine operation is shown in Figures 9 and 10 respectively. Ignition delay decreased with increased gas flow rates of both hydrogen and HCNG respectively and the CRDi version showed further reduction in the ID when compared to CMFIS operation. Higher injection pressure of RuOME in CRDi ensures uniform mixing of fuel combinations and hence lowers the ID. Hydrogen has higher flame speed and the advanced combustion phasing lowers the ignition delay compared to HCNG. However, gaseous fuel mixing with injected fuel requires more time leading to decreased chemical kinetics and the increased flow rates of both gases showed longer combustion duration with injected RuOME. At higher injection pressures of CRDi, combustion duration were found to be slightly lowered due to higher combustion temperatures with gas induction in general and hydrogen induction in particular which results into lowered combustion duration when compared to HCNG due to its comparatively higher flame velocity. For the same flow rate of HCNG and hydrogen $(0.1 \mathrm{~kg} / \mathrm{h})$, RuOME-Hydrogen with CRDi resulted in $16.4 \%$ decreased ignition delay compared to CMFIS, respectively. Similarly, for the same flow rate of HCNG and hydrogen $(0.1$ 


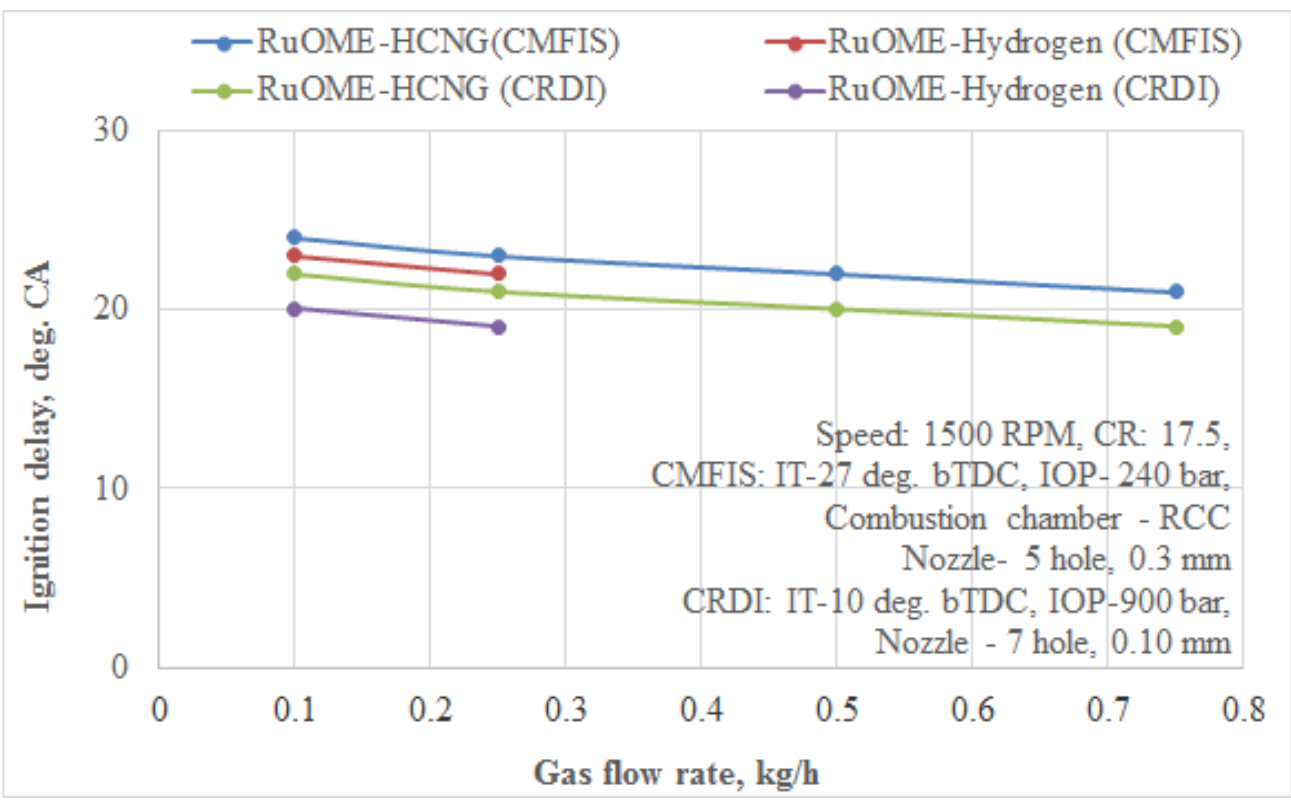

Figure 9. Effect of gaseous fuel flow rate $(\mathrm{kg} / \mathrm{h})$ on the ignition delay

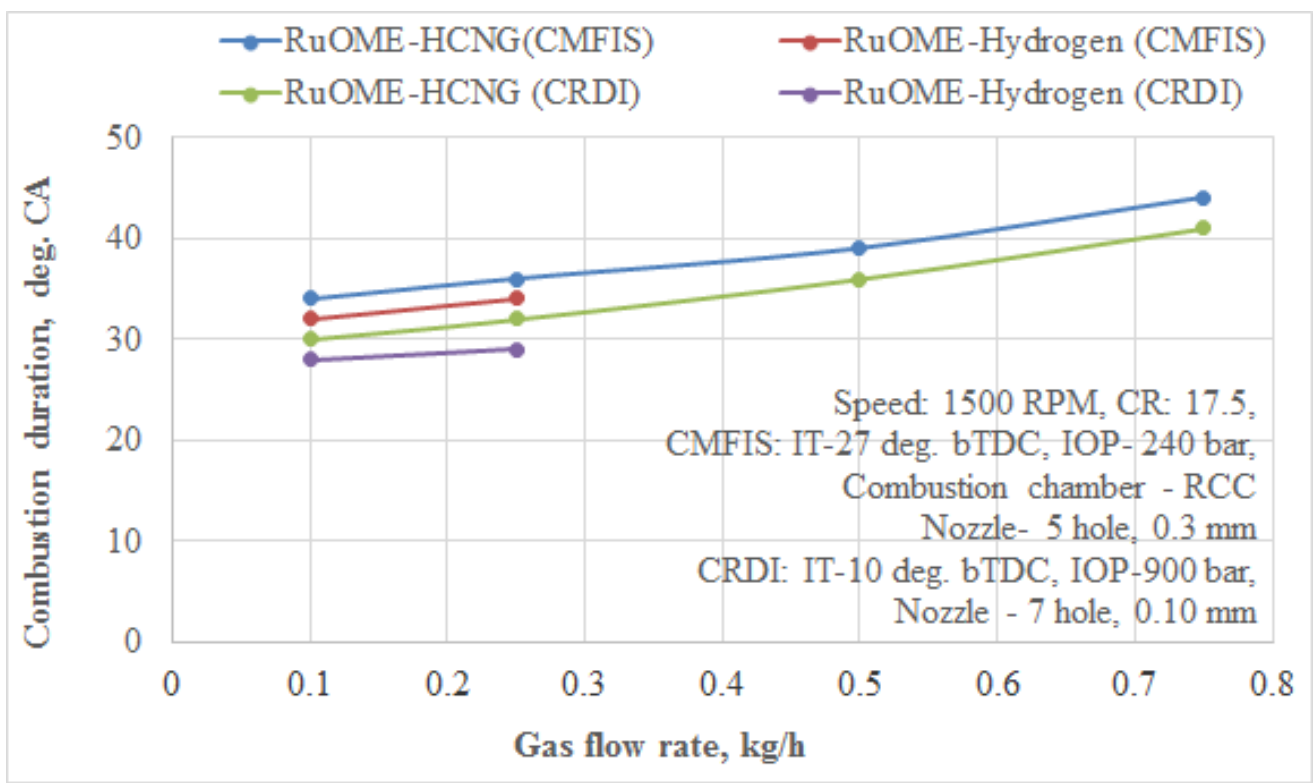

Figure 10. Effect of gaseous fuel flow rate $(\mathrm{kg} / \mathrm{h})$ on the combustion duration

$\mathrm{kg} / \mathrm{h}$ ), RuOME-Hydrogen with CRDi resulted in 6.9\% decreased combustion duration compared to RuOMEHCNG with CMFIS, respectively.

The variation of cylinder pressure and heat release rate with crank angle for both CMFIS and CRDi facilitated dual fuel engine with selected fuel combinations is shown in Figures 11 and 12. Cylinder pressures were higher for dual fuel operation when operated on CRDi facility for hydrogen gas induction at higher loads when compared to HCNG. The reasons for the observed trends could be due to rapid combustion of fuel combinations with higher combustion temperatures and increased premixed combustion phase obtained with hydrogen operation on CRDi facility. The engine operation was smooth with acceptable increased NOx emission levels.

Heat Release Rate (HRR) for both CMFI and CRDi dual fuel engine operation is shown in Figure 12 for selected fuel combinations. Higher heat release rate for the CRDi operation with hydrogen is caused mainly due to higher calorific value and flame speed of the gas which advances combustion. Therefore, CRDi operation with hydrogen induction showed significant effect on increased premixed combustion phase than diffusion combustion. Similar results were found in the literature [Saravanan N 2008, 2010]. Higher premixed combustion was observed with RuOME-Hydrogen (CRDi) when compared to RuOME-HCNG combination at 80\% load.

\section{Estimation of Uncertainty}

Measurement taken during experimentation has a corresponding uncertainty and ultimately it limits the conclusions drawn. It is related to the measurement parameter, equipment and measurement process. Random 


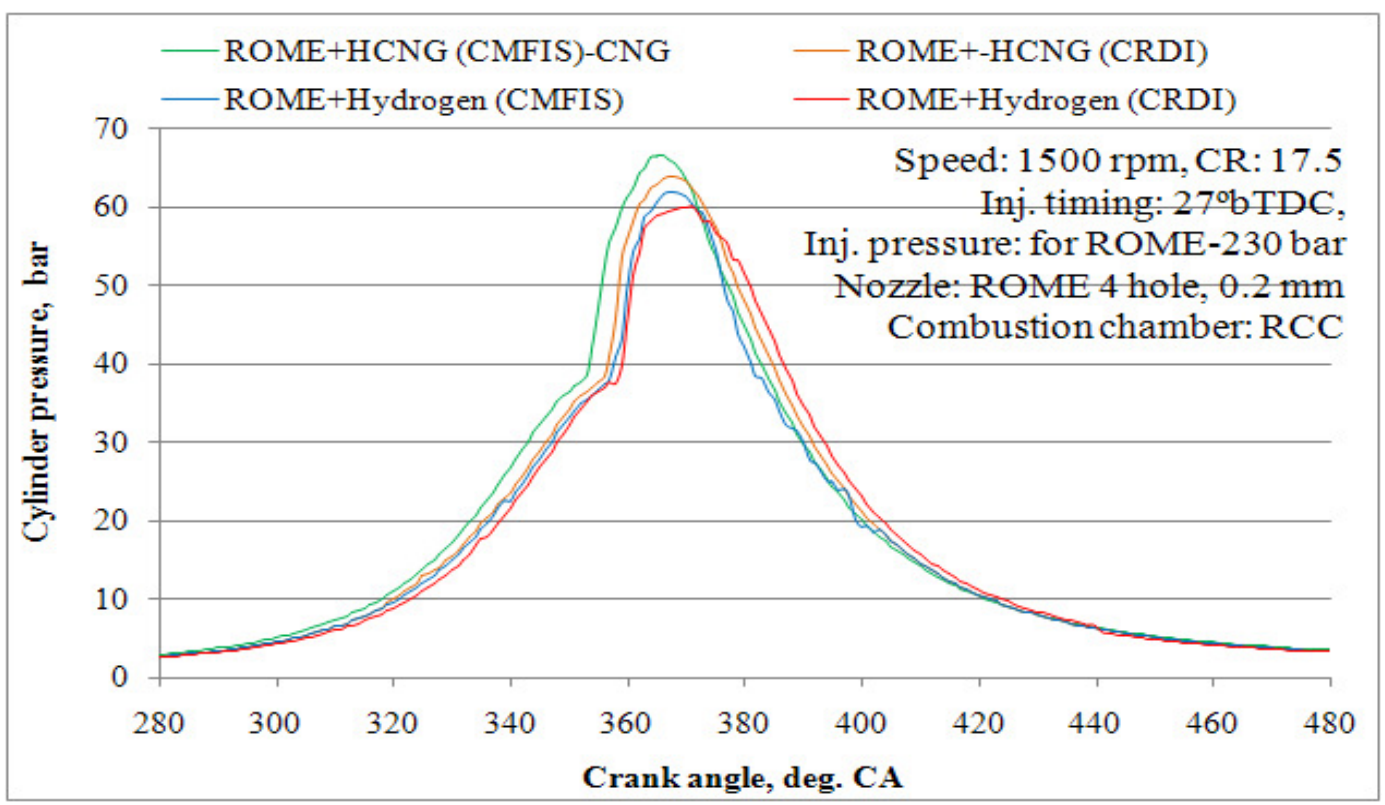

Figure 11. Effect of gaseous fuel flow rate $(\mathrm{kg} / \mathrm{h})$ on the cylinder pressure with respect to crank

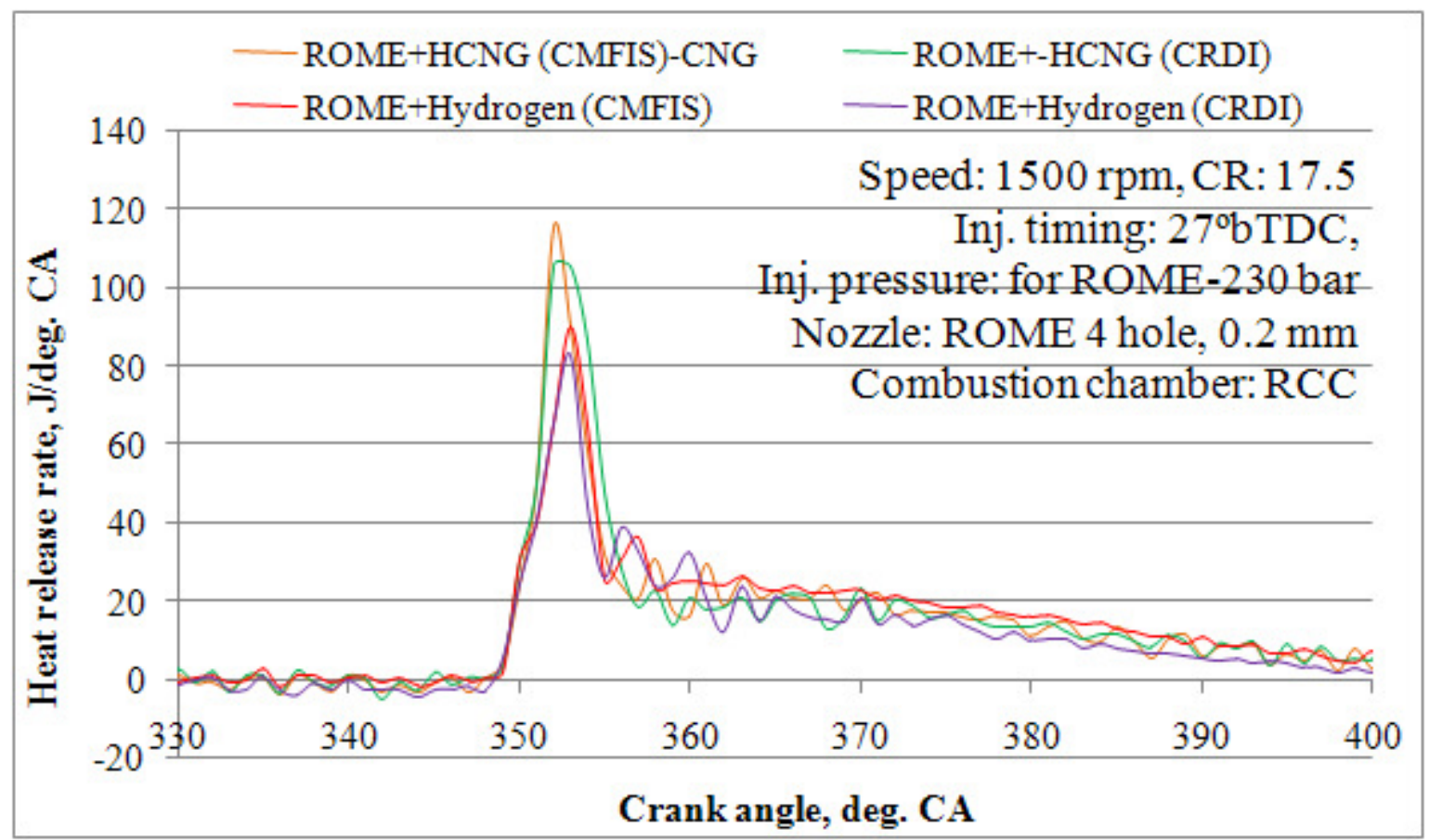

Figure 12. Effect of gaseous fuel flow rate on the heat release rate

errors are due to fluctuations resulted from multiple trials of measurement. However, systematic errors can be corrected with calibration of the instruments. The uncertainties recorded for different parameters were found to be $1.8,17.8,5.4,4.5,13.8 \%$ for BTE, smoke opacity, CO, and NOx respectively, at $80 \%$ load.

\section{Conclusions}

Exhaustive experimentation on dual fuel engines fueled with renewable fuels of RuOME and gaseous fuels of HCNG and Hydrogen using CMFIS and CRDi injection facilities were undertaken and from the study the following conclusions were drawn.

Dual fuel engine operation with renewable fuels can provide acceptable BTE with reduced emissions of smoke and NOx. Developed test rig with CRDi injection facility showed improved engine performance on clean burning fuels of hydrogen and HCNG respectively when compared to low pressure pilot fuel injection in CMFIS. The high pressure (900 bar) injection of RuOME and closer to TDC (10 ${ }^{\circ}$ BTDC) enabled uniform mixing of the fuel combinations which is difficult to achieve with CMFIS facility. Inducting gaseous fuels through the intake manifold can conserve the pilot injected (liquid) fuel quantity, and helps to decrease the smoke and NOx emissions as well. Dual fuel operation with a Hydrogen flow rates of $0.25 \mathrm{~kg} / \mathrm{h}$, injection timing of $10^{\circ} \mathrm{bTDC}$, injection pressure of 
900 bar and CR 17.5 resulted in improved performance and lowered emission levels. Precise injection of gaseous fuels in the manifold and port injection along with CRDi facilities can further give more flexibility on power and emission balance.

\section{REFERENCES}

Akhilendra Pratap Singh, Anuj Pal, Avinash Kumar Agarwal. (2016). Comparative particulate characteristics of hydrogen, CNG, HCNG, gasoline and diesel fueled engines, Fuel, Volume 185, pp 491-499.

Apostolescu, N., Chiriac, R. (1996). A study of combustion of hydrogen-enriched gasoline in a spark ignition engine, SAE Paper No. 960603, 1-10.

Bhuiya M.M.K., Rasul M.G., Khan M.M.K., Ashwath N., Azad A.K., Hazrat M.A. (2016). Prospects of 2nd generation biodiesel as a sustainable fuel - Part 2: Properties, performance and emission characteristics, Renewable and Sustainable Energy Reviews, 55, pp. 1129-46.

Lee J. T., Kim Y. Y., Caton J. A. (2002). The development of a dual injection hydrogen fueled engine with high power and high efficiency, Proceedings of the 2002 Fall Technical Conference of the ASME Internal Combustion Engine Division, No. ICEF2002-514, New Orleans, Louisiana, USA, 323-333.

M. Senthil Kumar, M. Jaikumar. (2014). Studies on the effect of hydrogen induction on performance, emission and combustion behaviour of a WCO emulsion based dual fuel engine, International Journal of Hydrogen Energy, Vol 39, Issue 32, pp 18440-50.

Masood M., Ishrat M.M., Reddy A.S. (2007). Computational combustion and emission analysis of hydrogen diesel blends with experimental verification, Int. J. Hydrogen Energy 32, 2539-47.

Paul A., Bose P., Panua Raj Sekhar, Banerjee R. (2013). An experimental investigation of performance-emission trade off of a CI engine fueled by diesel-compressed natural gas (CNG) combination and diesel-ethanol blends with CNG enrichment, Energy, Vol.55, pp.787-802.

Qian Y. J., Zuo C. J., Xu J. T. H. M. (2011). Effect of intake hydrogen addition on performance and emission characteristics of a diesel engine with exhaust gas recirculation, proceedings of the institution of mechanical engineers, Journal of Mechanical Engineering Science, 225, 1919- 25.

R.S. Hosmath, N.R. Banapurmath, S.V. Khandal, V.N. Gaitonde, Y.H. Basavarajappa, V.S. Yaliwal. (2016). Effect of compression ratio, CNG flow rate and injection timing on the performance of dual fuel engine operated on honge oil methyl ester (HOME) and compressed natural gas (CNG), Renewable Energy, Vol 93, pp 579-590.

Saravanan N., Nagarajan G. (2010). Performance and emission studies on port injection of hydrogen with varied flow rates with Diesel as an ignition source, Applied Energy, Vol.87, pp. 2218-29.

Saravanan N., Nagarajan G., Kalaiselvan K.M., Dhanasekaran C. (2008). An experimental investigation on hydrogen as a dual fuel for diesel engine system with exhaust gas recirculation technique, Renewable Energy, Vol.33, Issue 3, pp. 422-427.

Thangaraja Jeyaseelan, Pramod S Mehta. (2015). Reducing NO in a Biodiesel Fueled Compression Ignition Engine - An Experimental Study, Society of Automotive Engineers, paper no: 2015-24-2483.

H.K. Imdadul, H.H. Masjuki, M.A. Kalam, N.W.M. Zulkifli, Abdullah Alabdulkarem, M.M. Rashed, Y.H. Teoh, H.G. How Higher alcohol-biodiesel-diesel blends: An approach for improving the performance, emission, and combustion of a light-duty diesel engine, Energy Conversion and Management, Volume 111, 1 March 2016, Pages 174-185.

V.S. Yaliwal, N.R. Banapurmath, R.S. Hosmath, S.V. Khandal, Wojciech M. Budzianowski. (2016). Utilization of hydrogen in low calorific value producer gas derived from municipal solid waste and biodiesel for diesel engine power generation application, Renewable Energy, Vol 99, pp. 1253-61

Yaliwal V.S., Banapurmath N.R., Gireesh N.M., Hosmath R.S., Teresa Donateo, Tewari P.G. (2016). Effect of nozzle and combustion chamber geometry on the performance of a diesel engine operated on dual fuel mode using renewable fuels, Renewable Energy, Volume 93, 2016, Pages 483-501.

Ying Wang, Hong Liu, Chia-Fon F. Lee. (2016). Particulate matter emission characteristics of diesel engines with biodiesel or biodiesel blending: A review, Renewable and Sustainable Energy Reviews, Vol 64, pp 569-581 